Rural poverty dynamics and impact of intervention programs upon chronic and transitory poverty in northern Ethiopia

Fredu Nega, ${ }^{\mathrm{a}, \mathrm{b}^{*}}$ Erik Mathijs $^{\mathrm{b}}$, Josef Deckers ${ }^{\mathrm{b}}$, Mitiku Haile ${ }^{\mathrm{a}}$, Jann Nyssen $^{\mathrm{c}}$ and Eric Tollens $^{\mathrm{b}}$

${ }^{a}$ Mekelle University, Mekelle, Ethiopia

${ }^{\mathrm{b}}$ Catholic University of Leuven, Leuven, Belgium

${ }^{\mathrm{c}}$ Gent University, Gent, Belgium

A paper selected for presentation at the 2008 African Economic Conference

12-14 November 2008

Tunis, Tunisia

* Corresponding author. Division of Agricultural and Food Economics, Catholic University of Leuven, Willem de Croylaan 42, 3001 Heverlee; e-mail: tfredu@yahoo.com 


\title{
Rural poverty dynamics and impact of intervention programs upon chronic and transitory poverty in northern Ethiopia
}

\begin{abstract}
Using a three year panel data set of rural households in the Tigray region of northern Ethiopia, we examine the dynamics of poverty and the impact of two intervention measures - the food for work (FFW) and the food security package (FSP) programs upon poverty by disaggregating total poverty into its transient and chronic components. Poverty in the region is predominantly chronic. Results of matching estimators indicate that the FSP program has a significant negative effect on total and chronic poverty, but not on transient poverty. Households involved in the program have on average lower levels of total and chronic poverty than households not involved in the program. The FFW on the other hand does not significantly influence any of the three forms of poverty. Tertile regressions, however, reveal that the FFW benefits households in the richest and the middle tertiles.
\end{abstract}

Keywords: Poverty dynamics, chronic poverty, transitory poverty, food for work, food security package, Tigray, Ethiopia 


\section{Introduction}

Conventional poverty profile and poverty status measures provide useful information on the level of poverty, characteristics of the poor and the poverty correlates thereof. This, however, is not sufficient to combat poverty, partly because the correlates of poverty profiles are different from the dynamic process that determines a household's movements into and out of poverty. The lack of an inter-temporal dimension in the conventional measure is one of its criticisms and its presence provides a useful insight into what determines movements into and out of poverty and why some households remain poor.

The study of poverty dynamics requires panel data and the lack of it has been the limiting factor to study poverty dynamics in developing countries until recently. Over the last decade, a growing amount of panel data sets for developing countries has enabled researchers to start addressing the movements in poverty and the factors explaining these movements. Baulch and Hoddinott (2000) bring together recent studies on poverty dynamics in the developing world. In Ethiopia, several research papers (Dercon and Krishnan, 2000; Bigsten and Shimeles, 2004; Dercon, 2005; Swanepoel, 2005) have analyzed the dynamics of poverty but none have looked at the impact of intervention programs in place to fight poverty.

In the Tigray region of northern Ethiopia, two intervention programs - the food or cash for work (FFW) program and the household level food security package (FSP) program are widely implemented to fight poverty and ensure food security. By engaging the rural poor in public works such as the construction of rural roads, dams, and soil and water conservation activities against payment either in cash or in kind, the FFW program has a short-term objective of protecting the poor against shocks (consumption smoothing) as well as a long-term objective of poverty reduction, growth enhancement and natural resource conservation. The household level FSP program on the other hand intends to secure food at household level by diversifying the income base of the poor through provision of resources (credit) for a range of activities in a package. Identifying the basic interest of the rural poor and providing the required resources, technical assistance and training to engage in their choice of activities so as to secure food at household level and sustain income over time is the prime concern of the FSP program. 
A number of empirical studies have been conducted about the FFW program. Most focused on the efficiency in targeting (Clay et al., 1999; Devereux, 1999; Ravallion, 1999; Gebremedhin and Swinton, 2000; Haddad and Adato, 2001; Jayne et al., 2002) and others on the mode of payment - cash versus food (Faminow, 1995; Dorosh and Haggblade, 1997; Arndt and Tarp, 2001). Despite the importance of FFW programs to household welfare, studies on the impact of the programs on welfare are limited. There is a small body of research that assesses the impact of food aid programs on household food security and welfare and to a more limited extent, nutrition (Barret, 2002). Important exceptions include Quisumbing (2003), Dercon and Krishnan (2004), Yamano et al. (2005) and Holden et al. (2006). In a recent paper, Gilligan and Hoddinott (2007) examined the importance of FFW on consumption, food security and assets in rural Ethiopia.

Given the objectives of the programs - smoothing consumption in the short run and lifting income of participants in the long run - the evaluation of the impact of these programs upon chronic and transient poverty is pertinent, an aspect which has never been studied before. Using a panel data set of 385 rural households in northern Ethiopia, we assess the level of chronic and transitory poverty and the importance of the FFW and FSP programs for the chronically poor and transiently poor households. The paper is organized as follows. In the section that follows, we briefly describe intervention programs in Tigray. Data and methodology are discussed in section 3. Section 4 discusses the dynamics of poverty by identifying the magnitude of poverty and the impact of FFW and FSP programs on chronic and transient poverty and section 5 concludes.

\section{Intervention programs in Tigray}

Tigray is the northern most state of Ethiopia. It is one of the most drought prone and food insecure regions. Tackling food security at household level, which stretches from making food available to the rural poor to mitigate transitory economic shocks through emergency relief and safety net mechanisms, to diversifying the income base of the poor, is arguably the most effective and direct way of poverty reduction envisaged by the government. Among the programs implemented for this purpose are the Food for Work 
$(\mathrm{FFW})^{1}$ and an integrated household level extension program known as the Food Security Package (FSP) programs.

The FFW program has a long history in Ethiopia. It was first used in public works programs in the early 1960s. During the 1980s, the government managed an extensive national FFW soil conservation and afforestation project using labor brigades (Gebremedhin and Swinton, 2001). Today, FFW serves as a safety net for poor communities in food insecure areas. Poor households are made to work in public projects such as in the construction of rural roads for food wage. It is a way of utilizing the food aid available to development ends, while at the same time transferring food to the poor, i.e., a transition between emergency relief and the achievement of long term development objectives.

Tigray is one of the poorest regions in Ethiopia where the FFW program is widely used. Three food distribution systems are implemented in Tigray. In the first, free food is distributed to those unable to work. In the second, monthly payments of about $15 \mathrm{~kg}$ of food are paid to selected beneficiaries for monthly work of 5-6 days (a scheme locally known as the Employment Generating Scheme). In the third, FFW payments are made at a fixed daily rate of $3 \mathrm{~kg}$ and paid according to the number of days worked (Sharp, 1997). Tigray based FFW projects mainly focus on the construction of ponds, soil and water conservation structures, rural access roads, area enclosures and afforestation.

FFW projects envisaged until 2004 were more focused on relief oriented emergency system. Food insecurity in Ethiopia is normally understood in terms of recurrent food crises and famines, and responses to food insecurity have conventionally been dominated by emergency food based interventions (Deveruex et al., 2006). However, a significant portion of the aid recipients or those engaged in the FFW projects are not simply poor but chronically food insecure. Given their resource constraints and overall level of poverty, their food deficiencies are predictable which requires long term predictable support. Recognizing this, in 2004 a Productive Safety Net Program (PSNP) was introduced in Ethiopia. It marked a shift from a relief oriented emergency system to a productive and development oriented safety net. The program's objectives are to smooth household

\footnotetext{
${ }^{1}$ FFW includes all public work programs made against payment either in kind or in cash and the recently introduced Production Safety Net Program (PSNP)
} 
consumption by bridging production deficits in chronically food insecure farming households, protect household assets as a result of distress sales and create community assets (Devereux et al., 2006). The program increasingly provides cash rather than food support through labor intensive public works that address the underlying causes of food insecurity and through grants to households who cannot undertake public works (MoARD, 2004). Here, we do not make a distinction between the FFW program before 2005 and the PSNP since 2005. We consider both as FFW.

Besides the FFW program, the household level food security package (FSP) program was introduced in Tigray with the objective of furnishing the asset base of the poor to ensure food security and to increase and diversify the income base through the provision of adequate and efficient financial services, training and technical assistance. The program was launched in November 2002 with the overall aim of improving the livelihood of the rural households and raises the average annual income to $\mathrm{ETB}^{2} 18,000$ per household in a period of three years (Mirutse et al., 2006).

The household level FSP is a coordinated program that involves the main actors in the rural development of the region, mainly the regional Bureau of Agriculture and Rural Development (BoARD), the Food Security Office and the Dedebit Credit and Saving Institute (DECSI), the locally operating micro finance institute. Individual households capable of using loans for productive purposes are eligible for the program. A household can get financed for a range of activities (package) and loans are disbursed on an individual basis. Although the components of the package for which loans are granted differ from area to area to suit agro-ecological and other factors, the basic ones include livestock (oxen and cows), small animals (sheep and goats), poultry, beehives, seed and fertilizer. Depending on the type of activity, loan periods range from two to four years.

As measures to reduce poverty, the FFW and the FSP programs need be evaluated in terms of their short term and long term objectives. The short-run question is the ability of the programs (especially the FFW program) to effectively shield people who suffer transition income shocks. In this regard, when poor households face temporary shocks, they will have access to food in an exchange for their labor service in public works. This

\footnotetext{
${ }^{2}$ ETB is Ethiopian Birr, the local currency. The exchange rate in August 2008 was 1 US\$=ETB 9.6571
} 
helps the poor not only to have the minimum essential quantity of food necessary to maintain good nutrition, but also protects them from losing their meager assets. Thus, the short run objective of the programs need be evaluated in their ability to reduce transitory poverty.

Besides the transitorily poor, there are also the chronically poor households who are poor most of the time. The chronic poor are believed to have a low level of asset base to generate income. Thus, the long-run objective of the FFW and the FSP programs to reduce poverty is evaluated in their ability to foster income growth and wealth accumulation among the chronically destitute, i.e., in their ability to reduce chronic poverty.

\section{Data and methodology}

\subsection{Data}

The data considered here have been collected in three consecutive years - 2004, 2005 and 2006 - in four study tabias $^{3}$ in northern Ethiopia using a two-stage sampling design. The primary sampling units were tabias. Sample tabias were selected on the basis of secondary information collected from all Woredas ${ }^{4}$. In selecting the sample tabias, factors that affect socio-economic conditions such as distance to market, geographical location, the availability of both rain-fed agriculture and irrigation and size of tabia based on population were considered. A total of four tabias namely Ruba Feleg, Tsenkaniet, Arato and Siye were selected for the survey. The tabias selected are representative of the three agro-ecological zones of the Tigray region identified on the basis of altitude. Areas with altitude ranging from 1500-2300 m.a.s.l. are locally termed as woina dogua (i.e., midland areas), areas above 2300 m.a.s.l. are locally known as dogua (i.e., highland areas) and areas with altitude less than 1500 m.a.s.l. are termed as kola (i.e., lowland). Two of the tabias are in woina dogua, one is in dogua and the fourth in kola.

\footnotetext{
${ }^{3}$ Tabia is the smallest unit of local government in rural communities of the present day Tigray and each tabia consists of four villages. Hence, the study is conducted in 16 villages.

${ }^{4}$ Woreda is the second administrative unit above the tabia.
} 
A multi-purpose questionnaire was used to gather information on household income, expenditure, off-farm income, households' participation in the FFW and the FSP programs, household assets and local institutions alongside a host of other information related to production and sales. The survey questionnaire was administered to 100 households randomly selected from each tabia. A total of 400 households were selected for the survey. An important issue for panel data is the attrition rate across rounds. Only 9 households were lost in the second round and six more households in the third round. The attrition rate over the three years is nearly $4 \%$.

Data of the three rounds are directly comparable both in terms of content and timing. A standardized questionnaire was used in all rounds and the survey was conducted in a similar season.

\subsection{Measuring and decomposing poverty}

To analyze the impact of the FFW and the FSP programs on chronic and transitory poverty, we first determine the level of poverty and disaggregate it into its transitory and chronic components. We use consumption to measure poverty, for consumption is generally regarded as the best indicator of welfare in rural Ethiopia, because most people in the rural areas consume from their produce and do not earn regular off-farm income. A poverty line is constructed first by choosing a bundle of food items consumed by the poorest 50 percent. The quantity of each of the food items in the bundle is rescaled so as to give a predetermined level of minimum calorie requirement - $2200 \mathrm{kcal}$ per person per day; this is valued at area-specific prices. The food component of the poverty line is augmented with an allowance for non-food goods, consistent with the non-food spending of those households whose food spending is no more than adequate to afford the food component of the poverty line. ${ }^{5}$

\footnotetext{
${ }^{5}$ From the survey data a poverty line of ETB 1008 per person per year is constructed. The poverty line is constructed by first identifying the poorest $50 \%$ as a reference household deemed to be typical of the poor. Next, we identified the food items commonly consumed by the reference household to constitute the food bundle. In this case, a total of 21 food items are chosen and their quantity is determined in such a way that the bundle supplies a predetermined level of minimum calorie requirement $-2200 \mathrm{Kcal}$. Having selected the bundle of goods, we then valued it using a median price for each food item in the basket based on internal price data. The same basket of food items is valued by the corresponding price in each year and each study site to determine the cost of consuming the reference basket of food items. We expressed consumption expenditure in terms of 2006 prices. We followed the approach described in Ravallion and Bidani (1994) to estimate the required non-food share by examining the consumption behavior of the
} 
Following Jalan and Ravallion (2000), we decomposed poverty into its chronic and transitory components. They define transient poverty as the contribution of consumption variability over time to expected consumption. The non-transient component (chronic poverty) is the poverty that remains when inter-temporal variability in consumption has been smoothed out (Jalan and Ravallion, 2000). To formally state, assume consumption is used as welfare indicator and let $\left(\mathrm{y}_{\mathrm{i} 1}, \mathrm{y}_{\mathrm{i} 2}, \ldots, \mathrm{y}_{\mathrm{iT}}\right)$ be household i's consumption stream over $\mathrm{T}$ dates and $\mathrm{p}$ is some well-defined poverty measure, such as those in the FosterGreer-Thorbecke class of poverty measures (Foster et al., 1984), the inter-temporal aggregate measure of poverty of household $i$ is:

$$
p_{i}=p\left(y_{i 1}, y_{i 2}, \cdots, y_{i T}\right)
$$

The household's total poverty $p_{i}$ is the expectation overtime of the poverty measure at each point in time $p_{i t}$ :

$$
p_{i}=\frac{1}{T} \sum_{t=1}^{T} p_{i t}
$$

where $p_{i t}$ is:

$$
p_{i t}=\left\{\begin{array}{cl}
\left(\frac{z-y_{i t}}{z}\right)^{\alpha} & \text { if } y_{i t}<z \\
0 & \text { if } y_{i t} \geq z
\end{array}\right.
$$

where $\mathrm{z}$ is the poverty line. Chronic poverty is the poverty at time mean consumption for all dates and is defined as:

reference household who can just afford the reference food bundle. The non-food share is estimated by regressing the share of total expenditure devoted to food of each household $i$ on a constant and the $\log$ of the ratio of consumption expenditures to the food poverty line

$$
s_{i}=\alpha+\beta \log \left(y_{i} / z^{f}\right)+\varepsilon_{i}
$$

where the value of the intercept $\alpha$ estimates the average food share of those households that can just afford the food bundle, i.e., those households whose expenditure equals the food poverty line $\left(y_{i}=z^{f}\right)$. The poverty line is given by: $z=z^{f}(2-\alpha)$. 


$$
c_{i}=p\left(y_{i}^{*}, y_{i}^{*}, \ldots, y_{i}^{*}\right)
$$

where $y_{i}^{*}$ is the mean consumption expenditure of household $\mathrm{i}$.

Equation (4) can be written as the expectation over time of the household's chronic poverty at each point in time $c_{i t}$, but since the household's chronic poverty does not change over time, $c_{i}=c_{i t}$ where:

$$
c_{i}=c_{i t}=\left\{\begin{array}{cl}
\left(\frac{z-y_{i}^{*}}{z}\right)^{\alpha} & \text { if } y_{i}^{*}<z \\
0 & \text { if } y_{i}^{*} \geq z
\end{array}\right.
$$

The transient component $\left(p_{i}^{t}\right)$ of $p($.$) is the portion that is attributable to inter-temporal$ variability in consumption and is given by netting out the chronic component from the aggregate measure.

$$
p_{i}^{t}=p_{i}-c_{i}
$$

Jalan and Ravallion employed the squared poverty gap (i.e., $\alpha=2$ in equations (3) and (5)) as a measure of poverty which satisfies both the additive assumption - poverty measure should be additive across households and overtime, and transfer axiom - the poverty function should be strictly decreasing and convex to penalize inequality amongst the poor. We use the same poverty measure - the squared poverty gap. Since the squared poverty gap gives more weight to the poorest of the poor, it serves the purpose of evaluating the impact of the FFW and the FSP programs as these programs are basically meant to serve the poorest of the poor.

\subsection{The impact of intervention programs upon chronic and transitory poverty}

After decomposing poverty into its chronic and transitory components, we analyze the impact of the FFW and the FSP programs on these two forms of poverty. Assessing the impact of any intervention requires making an inference about the outcomes that would have been observed for program participants had they not participated. 
Let $\mathrm{Y}_{1}$ be the outcome conditional on participation and $\mathrm{Y}_{0}$ the outcome conditional on non-participation, so that the impact of participation in the program is $\Delta=Y_{1}-Y_{0}$. For each household, only $\mathrm{Y}_{1}$ or $\mathrm{Y}_{0}$ is observed, which leads to a missing-data problem. Let $\mathrm{D}$ be an indicator variable equal to 1 if the household works in FFW and 0 otherwise. Similarly $\mathrm{D}=1$ if the household is beneficiary of FSP and 0 otherwise. Let $\mathrm{Z}$ denote a vector of observed individual characteristics used as conditioning variables. The most common evaluation parameter of interest is the average impact of the treatment on the treated (ATT) given as

$$
\begin{aligned}
A T T & =E(\Delta \mid Z, D=1)=E\left(Y_{1}-Y_{0} \mid Z, D=1\right) \\
& =E\left(Y_{1} \mid Z, D=1\right)-E\left(Y_{0} \mid Z, D=1\right)
\end{aligned}
$$

This parameter estimates the average impact among participants. Data on program participants identify the mean outcome in the treated state $E\left(Y_{1} \mid Z, D=1\right)$. The mean outcome in the non-treated $E\left(Y_{0} \mid Z, D=1\right)$ is not observed. We estimate the impact of the FFW and the FSP programs on total, chronic and transitory poverty levels using propensity score matching as a method of estimating the counterfactual outcome for participants (Rosenbaum and Rubin, 1983).

Let $\mathrm{P}=\operatorname{Pr}(\mathrm{D}=1 \mid \mathrm{Z})$ denote the probability of participating in the programs (FFW or FSP), i.e., the propensity score. Propensity score matching constructs a statistical comparison group by matching observations on FFW or FSP recipients to nonparticipants on similar values of P. Propensity score matching estimators are based on two assumptions:

a) matching assumes that conditional on $\mathrm{P}$, non-participants have the same mean outcomes as participants would have if they did not receive the program:

$$
E\left(Y_{0} \mid P, D=1\right)=E\left(Y_{0} \mid P, D=0\right)=E\left(Y_{0} \mid P\right)
$$

b) valid matches can be found for each program participants:

$\mathrm{P}<1$

If assumptions (a) and (b) are satisfied, then, after conditioning on $\mathrm{P}$, the $\mathrm{Y}_{0}$ distribution observed for the matched non-participant group can be substituted for the missing $\mathrm{Y}_{0}$ 
distribution for participants. Under these assumptions, the mean impact of the program is given by

$$
\begin{aligned}
A T T & =E\left(Y_{1}-Y_{0} \mid D=1\right) \\
& =E\left(Y_{1} \mid D=1\right)-E_{P \mid D=1}\left\{E_{Y}\left(Y_{0} \mid D=1, P\right)\right\} \\
& =E\left(Y_{1} \mid D=1\right)-E_{P \mid D=1}\left\{E_{Y}\left(Y_{0} \mid D=0, P\right)\right\}
\end{aligned}
$$

where the first term on the right hand side of the last expression can be estimated from the treatment group and the second term from the mean outcomes of the matched (on P) comparison groups.

For each program (FFW and FSP), we estimate the propensity score for participation in the program by a probit model using observable variables in the panel that include both determinants of participation in the programs and factors that affect the outcome. We match treatment and comparison observation using kernel matching. Following Heckman et al. (1997) and Smith and Todd (2005), the kernel matching estimator takes the form

(9) $A T T=\frac{1}{n_{1}} \sum_{i=I_{1}}\left\{Y_{1 i}-\frac{\sum_{j \in I_{0}} Y_{0 j} K\left(\frac{P_{j}-P_{i}}{a_{n}}\right)}{\sum_{k \in I_{0}} K\left(\frac{P_{k}-P_{i}}{a_{n}}\right)}\right\}$

where as stated above, $I_{1}$ is the treatment group of program participants, $I_{0}$ is the comparison group of non-participants, $\mathrm{K}(\bullet)$ is a kernel function and $a_{n}$ is a bandwidth parameter.

\subsection{Conditioning variables for program participation}

The construction of the unobservable counterfactual is the basic dilemma of impact evaluation. Measuring impact as the difference in mean outcomes between all households involved in either the FFW or the FSP and those not involved even controlling for program characteristics, may give a biased estimate of program impact. This bias arises if there are unobserved characteristics that affect the probability of participation in the outcome of interest. Two important sources of this selection bias include targeting of the 
program to recipients based on characteristics unobservable to the researcher and selfselection into the program by eligible recipients (Gilligan and Hoddinott, 2007).

The propensity score matching estimator used in this analysis helps to control for these sources of selection bias and provides reliable, low-bias estimates of program impact provided sufficient control variables relevant to modeling the program participation decisions are used (Heckman et al., 1997). Our data set contains a rich set of conditioning variables to control program participation decisions.

The FFW and the FSP programs are intended to serve the very poor. Although it is difficult to identify the poor, one way of judging the welfare level of households is on the basis of assets owned. Hence, we include the two basic assets in the rural economy - land and livestock owned. Lack of these assets is associated not only with program eligibility but also with the outcome variable - total, chronic and transitory poverty measured by the squared poverty gap. However, the direction of the association of poverty with assets that can be accumulated or depleted such as livestock is not clear. It could be that households are poor because they possess less livestock or households possess less livestock because they are poor. To avoid endogeniety problem, we have used lagged values of livestock owned, i.e., livestock owned in 2003 , a year before the survey period for which poverty is calculated.

Demographic variables (female headship, age of household head, number of adult household members, number of children under five, dependency ratio and family size) associated with program eligibility and the outcome variables are also included.

A household participates in these programs with the aim of securing additional income and/or diversifying its income base by investing in new activities. Thus, a household's decision is partly influenced by the available labor time and the alternative income sources at its disposal. To capture this effect, we include control variables of whether a household participates in non-farm wage employment and/or non-farm self-employment income generating activities. We also include membership in local institutions to indicate the breadth and depth of household social connectedness to identify the role of these connections and access to information in program participation. Detailed retrospective questions about shocks in the 2006 round of the socio-economic survey also allows us to construct control variables for crop loss due to drought, disease and pests; livestock loss 
due to animal disease or theft, and other losses such as death of a household member, serious illness of a member, separation of partners, judiciary and other problems.

Conceived as willing to improve themselves, local administrators favor households who prepare their own water wells or garden ponds in the selection of participants for the FFW and the FSP programs. To capture this effect, we include control variables on whether a household possesses its own water well or garden pond.

Besides the above common control variables that influence eligibility to FFW and FSP, program-specific variables are also included. In the rural areas of Tigray, households are required to work 20 days for free on communal activities such as soil and water conservation. Since participation in collective action is regarded as one of the essential conditions to participate in the FFW program, we include a control variable to capture whether a household participated in communal activities in 2004 and 2005. We also include the gap between the local market wage rate and the FFW wage rate interacted with male adult household members to identify household specific self selection.

For the FSP program, we include a control variable for households' access and indebtedness to other formal sources of credit such as loans from Dedebit Credit and Saving Institute (DECSI), Bureau of Agriculture, Women's Association and Cooperatives is considered. To be eligible to the FSP program, a household must not be indebted to any of the aforementioned formal institutions.

With this rich set of control variables one can capture many of the determinants of participation that are typically unobservable to the researcher, which helps to reduce a potentially significant source of bias in propensity score matching estimators. We find that the estimates of the FFW and the FSP programs are sensitive to the choice of variables used for conditioning participation, so we try various alternative specifications and present the results that appear most robust.

\section{Results}

We present our results by first showing the dynamics of poverty and then we explore the impact of the FFW and the FSP programs upon chronic and transitory poverty. 


\subsection{Dynamics of poverty}

\section{i) Short term mobility of households between 2004 and 2006}

The mobility of households between quintiles using transition matrix is shown in table 1 . The $\mathrm{ij}^{\text {th }}$ element of a transition matrix represents the percentage of households that moved from state $\mathrm{i}$ to state $\mathrm{j}$ in the period under consideration. The table indicates that most households at the two extreme quintiles - the bottom most (first quintile) and top most (fifth quintile) - stayed in the same quintile as compared to the middle level quintiles. Moreover, most households moved one quintile upward or downward.

Table 1 Transition matrix for quintiles of real consumption between 2004 and 2006

\begin{tabular}{rccccc}
\hline Quintiles & $\mathbf{1}$ & $\mathbf{2}$ & $\mathbf{3}$ & $\mathbf{4}$ & $\mathbf{5}$ \\
\hline $\mathbf{1}$ & 39 & 16 & 22 & 13 & 10 \\
$\mathbf{2}$ & 25 & 25 & 17 & 23 & 10 \\
$\mathbf{3}$ & 14 & 29 & 22 & 17 & 18 \\
$\mathbf{4}$ & 10 & 23 & 20 & 26 & 21 \\
$\mathbf{5}$ & 12 & 8 & 19 & 21 & 40 \\
\hline
\end{tabular}

The information contained in the transition matrix can be summarized into mobility index using Sharrocks Mobility Index (SMI). Sharrocks mobility index, M for a transition matrix $\mathrm{T}$ is given by

$$
M(T)=\frac{n-\operatorname{trace} T}{n-1}, \quad \text { where } n \text { is the number of states or categories }
$$

The index is normalized to take a value between 0 and 1 by dividing it by $n / n-1$. An SMI value close to one indicates higher mobility (Shorrocks, 1978). The transition matrix in table 1 above results in an SMI of 0.696, indicating relatively high mobility between 2004 and 2006. The index, however, does not give indication of the direction of mobility. Table 2 provides information on direction of mobility using poverty line by dividing households into three: the poor with consumption below the poverty line; the vulnerable with consumption between the poverty line and double this value, and lastly, the rich with consumption more than twice the value of the poverty line. 
Table 2 Transition matrix using poverty line between 2004 and 2006

\begin{tabular}{lccc}
\hline 2006 consumption $\longrightarrow$ & Below Z & Between $Z$ and 2Z & Above 2Z \\
2004 consumption $\downarrow$ & & & \\
\hline Below $Z$ & $212=61 \%$ & $124=36 \%$ & $10=3 \%$ \\
Between $Z$ and $2 Z$ & $11=33 \%$ & $19=58 \%$ & $3=9 \%$ \\
Above $2 Z$ & $1=17 \%$ & $3=50 \%$ & $2=33 \%$ \\
\hline
\end{tabular}

Since most households (nearly 90 percent) were below poverty line in 2004, it is important to see the movement of these households shown in the first row of table 2. Sixty one percent of the households who were poor in 2004 were also classified poor in 2006. Only 39 percent are able to cross the poverty line, out of which more than 90 percent are between the poverty line and double of it and the remaining 10 percent are able to cross twice the poverty line.

The transition matrices discussed above only consider movements between the initial year and the last year of the survey ignoring any movement in between. Table 3 summarizes the movement of households in each of the three survey years. It indicates that 45 percent of the households were persistently poor throughout the survey period. The percentage rises to 50 percent if the figure is counted out of those initially observed

Table 3 Poverty transition (2004 - 2006)

\begin{tabular}{lcc}
\hline Status $(2004 \rightarrow 2005 \rightarrow 2006)$ & Frequency & Percentage \\
$\mathrm{P}=$ poor; $\mathrm{NP}=$ not poor & & \\
\hline $\mathrm{P} \rightarrow \mathrm{P} \rightarrow \mathrm{P}$ & 174 & 45 \\
$\mathrm{P} \rightarrow \mathrm{P} \rightarrow \mathrm{NP}$ & 66 & 17 \\
$\mathrm{P} \rightarrow \mathrm{NP} \rightarrow \mathrm{P}$ & 38 & 10 \\
$\mathrm{P} \rightarrow \mathrm{NP} \rightarrow \mathrm{NP}$ & 68 & 18 \\
$\mathrm{NP} \rightarrow \mathrm{NP} \rightarrow \mathrm{NP}$ & 15 & 4 \\
$\mathrm{NP} \rightarrow \mathrm{NP} \rightarrow \mathrm{P}$ & 2 & 1 \\
$\mathrm{NP} \rightarrow \mathrm{P} \rightarrow \mathrm{NP}$ & 12 & 3 \\
$\mathrm{NP} \rightarrow \mathrm{P} \rightarrow \mathrm{P}$ & 10 & 3 \\
\hline
\end{tabular}


poor. It means that one-half of the households observed poor in the initial year of the survey were not able to come out of poverty either in the following year or the last year of the survey. The non-poor category (households observed non-poor throughout the survey) accounts for 4 percent and the remaining (51\%) have experienced movements in poverty - some (38\%) are escapers and the remaining (13\%) are entrants.

\section{ii) The magnitude of chronic and transitory poverty}

To examine the nature of poverty further, we calculated total, chronic and transient poverty using the Jalan and Ravallion measures described above. The results are shown in Table 4.

Table 4 Decomposition of total poverty into chronic and transient poverty

\begin{tabular}{lllllll}
\hline & Total & Percent & Chronic & Percent & Transient & Percent \\
\hline Full sample & 0.157 & 100 & 0.102 & 65 & 0.055 & 35 \\
Arato & 0.104 & 100 & 0.046 & 44 & 0.058 & 56 \\
Rubafeleg & 0.162 & 100 & 0.122 & 75 & 0.04 & 25 \\
Siye & 0.183 & 100 & 0.123 & 67 & 0.06 & 33 \\
Tsenkaniet & 0.175 & 100 & 0.114 & 65 & 0.061 & 35 \\
\hline
\end{tabular}

Table 4 indicates that chronic poverty constitutes $65 \%$ of the total poverty and only the remaining (35\%) is transitory. Thus if one is interested in the poorest of the poor, table 4 indicates that most of the squared poverty gap results from low average income levels rather than fluctuations of income. However, the proportion of chronic and transitory poverty shows significant variation among the study areas. The proportion of chronic poverty ranges from 44 percent in Arato to 75 percent in Rubafeleg. The contribution of chronic to total poverty is higher in northern Ethiopia as compared to a study made by Swanepoel (2005) for rural Ethiopia using the Ethiopian Rural Household Survey (ERHS) panel data. Using the same measure of poverty ( $\alpha=2$ ), Swanepoel (2005) finds that chronic poverty amounts to 49 percent of total poverty in rural Ethiopia. In another study, Dercon and Krishnan (2000) find a chronic poverty ranging from 75 to 92 percent 
of the total. However, their result is reported for a poverty gap measure $(\alpha=1)$ and it is not directly comparable.

\subsection{The poverty impact of the FFW and FSP programs}

Participation in the FFW and FSP programs, the dependent variables in the impact assessment analysis, takes the value of 1 if a household participates in the programs and 0 otherwise. Table 5 shows a description of participation in each program. Participation in the FFW program is considered over the whole panel period (2004-2006); whereas participation in the FSP program is for the first two years of the panel (2004 and 2005). In analyzing participation in the FSP program, the last year of the panel (2006) is not considered because the welfare impact of loans obtained in 2006 could not be observed in the same period.

Table 5 Participation in the FFW and FSP programs

\begin{tabular}{lr}
\hline Description & $\begin{array}{c}\text { Full } \\
\text { sample }\end{array}$ \\
\hline Number of HHs in the panel (2004-2006) & 385 \\
Share of HHs participating in the FFW program (2004-2006) & 80 \\
Average number of days worked in the FFW program (2004-2006)* & 191 \\
Share of HHs participating in the FSP program (2004 and 2005) & 50
\end{tabular}

* Average number of days is calculated for those who participated in the FFW program.

\section{i) Propensity Score}

For both the FFW and the FSP programs, probit models were estimated using a broad set of control variables to construct propensity scores used to match program participants to non-participants. In propensity score matching, it is important to condition the match on variables that are highly associated with the outcome variables (Heckman and NavarroLozano, 2004). However, as Smith and Todd (2005) noted, there is little guidance on how to select the set conditioning variables used to construct the propensity score.

As stated in section 3.4 above, we focused on finding a set of conditioning variables that on theoretical grounds and based on information in the survey data should be highly 
associated with the probability of participating in each program and with the outcomes of interest. In a series of t-tests, we tested the balancing property of each of the probit specifications to ensure that the mean propensity score is not different for the treatment sample and the sample of comparison observations at various levels of propensity scores.

Table 6 presents the model of participation in each program used to create propensity scores for the matching algorithm. For the FSP, the control variables chosen include land owned, household demographic variables (female headship, age of household head, family size, number of adult household members), whether the household head has at least a primary level of education, whether the household experienced reporting crop shock, livestock shock, and illness shock from 2004 to 2006; the number of livestock owned in 2003 in tropical livestock units, whether the household possesses a garden pond and water well, whether the household earns non-farm wage income, whether the household earns non-farm self-employment income, whether the household is free of any financial indebtedness to other formal institutions that provide loans to farmers in the area and finally a household's social connectedness measured by membership in local associations

For the FFW program, the estimated propensity scores were based on the same set of control variables used in the FSP except for financial indebtedness of a household to other formal institutions which is not required to have access to the FFW program. Two new control variables are added in estimating propensity scores in the FFW program. One is whether the household participated in collective work in 2004 and 2005, and the second is the wage differential between FFW and the local agricultural labour market interacted with the number of adult male household members. 
Table 6 Probit estimates for participation in FSP and FFW programs

\begin{tabular}{|c|c|c|c|c|}
\hline \multirow[t]{2}{*}{ Variables } & \multicolumn{2}{|c|}{ FSP $^{\mathrm{a}}$} & \multicolumn{2}{|c|}{$\mathrm{FFW}^{\mathrm{a}}$} \\
\hline & $\begin{array}{c}\text { Estimates }^{b} \\
(\hat{\beta})\end{array}$ & t-value & $\begin{array}{c}\text { Estimates }^{b} \\
(\hat{\beta})\end{array}$ & t-value \\
\hline Female headship $\mp$ & 0.133 & $(0.71)$ & 0.020 & $(0.07)$ \\
\hline Age of household head & $-0.014 * * *$ & $(-2.81)$ & $-0.015^{* *}$ & $(-2.22)$ \\
\hline Number of adult household members & $0.123 *$ & $(1.70)$ & 0.126 & $(0.93)$ \\
\hline Family size & 0.016 & $(0.34)$ & -0.011 & $(-0.16)$ \\
\hline Dummy for household head education $\mp$ & -0.084 & $(-1.27)$ & -0.087 & $(-0.81)$ \\
\hline Water well干 & 0.261 & $(1.17)$ & 0.371 & $(1.21)$ \\
\hline Garden pond $\mp$ & $0.470 * * *$ & $(2.99)$ & 0.322 & $(1.24)$ \\
\hline Social capital & $0.015 * * *$ & $(3.20)$ & $0.014^{* *}$ & $(2.29)$ \\
\hline Livestock owned in Tropical livestock unit & 0.020 & $(0.71)$ & -0.059 & $(-1.42)$ \\
\hline Non-farm wage income $\mp$ & -0.047 & $(-0.27)$ & $1.028 * * *$ & $(4.17)$ \\
\hline Non-farm own business income $\mp$ & 0.137 & $(0.88)$ & $-0.496 * *$ & $(-1.99)$ \\
\hline Crop shock $\mp$ & 0.159 & $(1.08)$ & $-0.599 * * *$ & $(-2.65)$ \\
\hline Livestock shock $\mp$ & $-0.356 * *$ & $(-2.00)$ & -0.297 & $(-1.14)$ \\
\hline Illness and/or death shock $\mp$ & -0.083 & $(-0.43)$ & $-0.552 * *$ & $(-2.01)$ \\
\hline Land owned (Tsimdi) ${ }^{c}$ & 0.004 & $(0.16)$ & 0.047 & $(1.09)$ \\
\hline Financial indebtedness to formal institutions & $-0.271 *$ & $(-1.78)$ & & \\
\hline Collective action in $2004 \mp$ & & & $0.859 * * *$ & $(2.99)$ \\
\hline Collective action in $2005 \mp$ & & & $0.431 *$ & $(1.84)$ \\
\hline Market-FFW wages differential * adult male & & & 0.002 & $(0.03)$ \\
\hline Log likelihood & -238.946 & & -100.410 & \\
\hline chi2 & 55.81 & & 161.24 & \\
\hline $\mathrm{P}$ & 0.000 & & 0.000 & \\
\hline
\end{tabular}

Note: $\quad{ }^{a}$ Dependent variable equals 1 if household participated in the program (worked in FFW program or got loan from FSP program) between 2004 and 2006 in the case of FFW program and until 2005 for FSP program, and 0 otherwise.

b Results are presented as the change in the probability for an infinitesimal change in each continuous $\mathrm{X}$ variable, and as the discrete change in the probability from changing the value from 0 to 1 for dummy X variables (marked with a $\mp$ ). Estimates include village dummy variables (not shown)

${ }^{\mathrm{c}}$ Tsimdi is an area of land that can be plowed by a pair of oxen in a day and is approximately equal to one-fourth of a hectare.

* significant at $10 \%$ level; ** significant at $5 \%$ level; *** significant at $1 \%$ level 


\section{ii) Matching results}

Table 7 presents estimates of the average impact of participation in the FFW and the FSP programs. The outcomes considered include total poverty, chronic poverty and transient poverty. The squared poverty gap is used to measure all three forms of poverty.

Panel A of table 7 shows the average level of total, chronic and transient poverty along with the average differences and t-values for treated and control groups, where treatment is defined by participation in the FSP program. The results indicate that participation in the FSP program significantly affects total and chronic poverty. For the unmatched samples, the "naïve" estimates of the effect of the FSP program on total poverty measured by the squared poverty gap is -0.022 , meaning that households who participate in the FSP are expected to have lower total poverty measured by the poverty gap by 0.022 points, on average, than households who do not participate in the FSP program. As shown in the table this difference between the treated (participants in the FSP) and the untreated (non-participants) is substantial (-0.032) when respondents are matched on household socio-demographic, asset and other variables indicated in table 6.

Participants in the matched sample have poverty levels, measured by the squared poverty gap, that are on average nearly $18 \%$ lower than non-participants in the same sample. This suggests that the FSP program has a causal influence on total poverty when individuals are matched on the relevant socio-demographic, assets and other covariates. Hence, if we had two hypothetical households matched on those socio-demographic, asset and other variables in table 6 but were to make one of them participate in the FSP (i.e., get access to food security loan for a package of activities and training) she would have a poverty level on average $18 \%$ lower than the other individual not involved in the program.

For chronic poverty, a similar trend is reflected. Treated households in the matched sample have lower levels of chronic poverty than non-participants in the same sample. Program participants have a chronic poverty level that is on average 0.027 points (i.e., $23 \%$ ) lower than non-participants and the difference is statistically significant at the $10 \%$ level of significance. On the other hand, for the unmatched sample, the difference in chronic poverty between participants and non-participants vanishes $(\mathrm{P}>0.10)$. 
The third outcome estimated for program participants and non-participants is transitory poverty. The FSP program has no significant influence on transient poverty. Although the difference in transitory poverty between participants and non-participants is negative, it is not statistically significant and hence not different from zero $(\mathrm{P}>0.10)$.

In panel $\mathrm{B}$, the same analysis of the outcome variables is done, but this time the treatment variable being whether the household participates in the FFW program. The results indicate that there is no difference on the three measures of poverty (total, chronic and transient) for both program participants and non-participants, suggesting that the FFW program has no significant influence on chronic and transient poverty as measured by the squared poverty gap.

In the bottom portion of table 7 , we estimate the impact of FFW on total, chronic and transient poverty by tertiles of total poverty to see if the average impact masks significant impacts of the FFW program for some participants. Lower tertile means households with a low level of total poverty and hence higher welfare, and higher tertile means lower welfare. The estimates show variation in the impact of participation in the FFW program across the three forms of poverty. Participants and non-participants are not different in terms of transient poverty but there are significant differences in total and chronic poverty for tertiles one and two respectively. Participants in tertile 1 (the tertile with the lowest level of poverty or equally, the tertile with the highest level of welfare) have a lower level of total poverty than non-participants in the same tertile. This means that the FFW program reduces severity of poverty for participants in the upper welfare group. The same effect, however, is not observed for the second and the third tertiles. The difference in total poverty among participants and non-participants in these two tertiles is not different from zero $(\mathrm{P}>0.10)$. On the other hand, participants in the second tertile have lower levels of chronic poverty than non-participants in the same tertile. The difference in chronic poverty for the other tertiles, although negative, is not statistically significant $(\mathrm{P}>0.10)$.

To sum up, the FFW program has a significant and negative effect on total and chronic poverty for the richest and the middle tertiles respectively, but is not significant for the poorest tertile. This echoes the finding by Gilligan and Hoddinott (2007) in their analysis of the impact of Employment Generation Schemes (EGS) on household welfare in 
Table 7 Average outcome of total, chronic and transient poverty for matched groups of FSP and FFW program participants and non-participants

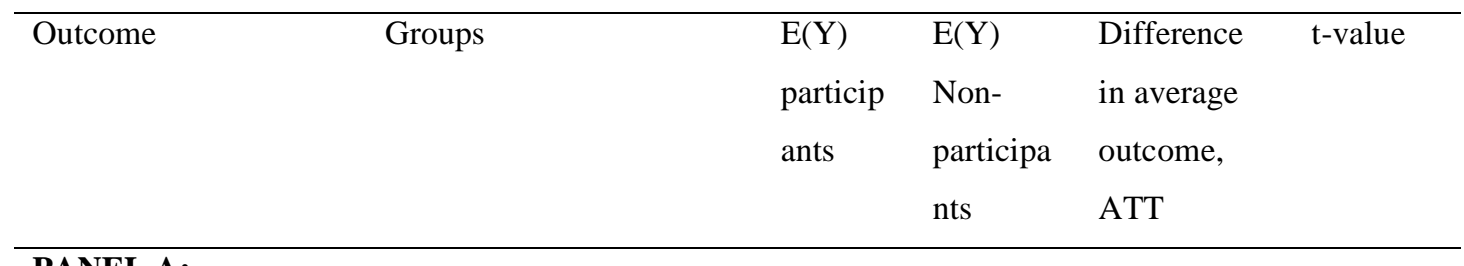

PANEL A:

Treatment: participation in FSP

Impact: Mean impact

\begin{tabular}{llllll}
\hline Total poverty & Unmatched & .146 & .168 & $-.022 *$ & $(-1.73)$ \\
\multirow{3}{*}{ Chronic poverty } & Matched & .142 & .174 & $-.032 * * *$ & $(-2.33)$ \\
& Unmatched & .094 & .11 & -.016 & $(-1.27)$ \\
\multirow{2}{*}{ Transient poverty } & Matched & .089 & .116 & $-.027 *$ & $(-1.94)$ \\
& Unmatched & .052 & .058 & -.006 & $(-1.11)$ \\
& Matched & .052 & .058 & -.006 & $(-0.95)$ \\
\hline
\end{tabular}

\section{PANEL B:}

Treatment: Participation in FFW program

Impact: Mean impact

\begin{tabular}{llcccc}
\hline Total poverty & Unmatched & .160 & .142 & .018 & $(1.11)$ \\
\multirow{3}{*}{ Chronic poverty } & Matched & .160 & .123 & .037 & $(1.04)$ \\
& Unmatched & .105 & .086 & .019 & $(1.19)$ \\
\multirow{2}{*}{ Transient poverty } & Matched & .106 &. .082 & .023 & $(0.71)$ \\
& Unmatched & .055 & .056 & -.001 & $(-0.16)$ \\
& Matched & .055 & .041 & .014 & $(0.86)$
\end{tabular}

Treatment: participation in FFW program

Impact: Mean impact by tertiles of total poverty measured by squared poverty gap

\begin{tabular}{llllll}
\hline Total Poverty & Matched in tetile 1 & 0.035 & 0.060 & $-0.026^{*}$ & -1.80 \\
& Matched in tertile 2 & 0.138 & 0.164 & -0.026 & -1.18 \\
Matched in tertile 3 & 0.290 & 0.322 & -0.032 & -1.17 \\
Chronic Poverty & Matched in tetile 1 & 0.008 & 0.016 & -0.008 & -0.97 \\
Transient Poverty & Matched in tertile 2 & 0.074 & 0.134 & $-0.059^{*}$ & -1.80 \\
& Matched in tertile 3 & 0.228 & 0.285 & -0.057 & -1.12 \\
& Matched in tetile 1 & 0.027 & 0.045 & -0.018 & -1.35 \\
& Matched in tertile 2 & 0.064 & 0.031 & 0.033 & 1.24 \\
\hline
\end{tabular}

* significant at $10 \%$;* significant at 5\%; *** significant at $1 \%$. 
Ethiopia. They find that the program [EGS] has no effect on the growth of household consumption or food consumption for households in the poorest tertile, but it has large, positive and significant effects on both outcomes of households in tertiles 2 and 3 (Gilligan and Hoddinott, 2007). One explanation given by Gilligan and Hoddinott (2007) is the difference in the number of days worked. EGS participants in the poorest tertile worked fewer days on average than their counterparts in the second and third tertiles.

A similar explanation holds true in this analysis too. The FFW participants in the richest tertile (tertile 1) worked on average more number of days than their counterparts in the second and third tertiles. Program participants in tertile one worked on average 194.3 days over the period 2004-2006, while those in the second and third tertiles worked 189.6 and 189.5 days respectively over the same period. The difference is even large if we consider the average number of days worked per adult household member or average per capita number of days worked (i.e., total number of days worked by a household divided by household size). The FFW participants in the richest tertile worked on average 93 days per adult household member, whereas the figure for program participants in the middle and the poorest tertiles is 75.9 and 73.5 days respectively. Similarly in terms of per capita number of days worked, program participants in the richest, middle and poorest tertiles worked 45.6, 31.4 and 31 days respectively. In all indicators, participants in the richest tertile participate more in the program followed by participants in the middle tertile. One reason for this observed difference in participation may be the tighter labor constraint in poor households (Barret and Clay, 2003; Gilligan and Hoddinott, 2007). Another reason could be poor targeting in the implementation of the program. Although it is believed that the FFW program is self targeted, i.e., the relatively wealthier households are less likely to participate due to the low wage, there is evidence that this is not the case. Solomon (2006) finds that households with higher farm income and oxen holding were more likely to take part in food-for-work programs in northern Ethiopia pointing to a leakage in targeting.

Besides differences in number of days worked, another explanation for differences in impact of the FFW on poverty for the three terciles could be that due to factors not explained by the substantial set of control variables used for matching participants to 
non-participants, the rich can complement income from the FFW by other sources and turn it to a more productive use and hence more lasting effects on poverty.

\section{Conclusions}

Using panel data of 385 rural households from the Tigray region of northern Ethiopia, we examined the dynamics of poverty and the impact of the FFW and the FSP programs on total, chronic and transitory poverty.

Poverty in Tigray is predominantly chronic. Matching results indicate that the FSP program significantly reduces total and chronic poverty. After matching participants in the FSP program with non-participants on the basis of some socio-demographic, asset and other variables, we find that the level of total and chronic poverty of the FSP program participants is respectively 18 and 23 percent lower than that of nonparticipants. The two groups, however, do not differ in terms of transitory poverty.

Participation in the FFW program, on the other hand, does not have a strong and significant effect on chronic and transitory poverty. Results disaggregated by tertiles of total poverty measured by the squared poverty gap show that benefits from the FFW program are skewed towards households in the richest and the middle tertiles.

These findings have important implications for anti-poverty measures. The predominantly chronic nature of poverty in our sample implies two things: a) anti-poverty measures should place emphasis on building the asset base of the poor to shift average income. The recent shift in the FFW program from a relief-oriented emergency system to the Productive Safety Net Program (PSNP) that targets to provide long-term predictable support to chronic food insecure households is commendable, and b) the fact that most poverty is chronic makes targeting possible. Despite this, targeting seems a problem in the anti-poverty measures especially in the FFW. The relatively rich households benefit more than the severely poor. 


\section{References}

Arndt, C. and F.Tarp (2001), "Who Gets the Goods? A General Equilibrium Perspective on Food Aid in Mozambique", Food Policy, 26(2), 107-119.

Barrett, C.B. (2002), "Food Security and Food Assistance Programs" in Gardner, B. and G. Rausser (eds), Handbook of Agricultural Economics, Volume 2, Elsevier.

Barrett, C.B. and D.C. Clay (2003). "How Accurate is Food-for-Work Self-Targeting in the Presence of Imperfect Factor Markets? Evidence from Ethiopia”, Journal of Development Studies 39(5), 152-80.

Baulch, R. and J. Hoddinott (2000), "Economic Mobility and Poverty Dynamics in Developing Countries", Journal of Development Studies 36 (6), 1-24.

Bigsten, A. and S. Abebe (2003), "The Dynamics of Poverty in Ethiopia", WIDER Research Paper No. 39

Clay, D.C., D. Molla and H. Debebe (1999), "Food Aid Targeting in Ethiopia: A Study of Who Needs It and Who Gets It", Food Policy, 24(3), 391-409.

Dercon, S. (2005), "Economic Reform, Growth and the Poor: Evidence from Rural Ethiopia", Journal of Development Economics 81, 1-24.

Dercon, S. and P. Krishnan (2000), "Vulnerability, Seasonality and Poverty in Ethiopia", Journal of Development Studies 36(6), 25 -53.

Dercon, S. and P. Krishnan (2004), "Food Aid and Informal Insurance" in Dercon, S. (ed), Insurance Against Poverty, Oxford University Press, USA.

Devereux, S. (1999), “Targeting Transfers: Innovative Solutions to Familiar Problems”, Institute of Development Studies Bulletin 30(2), 61-74.

Devereux, S., R. Sabates-Wheeler, T. Mulugeta and T. Hailemichael (2006), "Ethiopia's Productive Safety Net Program (PSNP): Trends in PSNP Transfer within Targeted Households", Institute of Development Studies, Sussex, UK and Indak International Pvt. L. C., Addis Ababa, Ethiopia.

Dorosh, P.A. and S. Haggblade (1997), "Shifting Sands: The Changing Case for Monetizing Project Food Aid in Bangladesh”, World Development 25(12), 20932104.

Faminow, M. (1995), "Issues in Valuing Food Aid: The Cash or In-Kind Controversy" Food Policy 20(1), 3-10. 
Foster, J.E., J. Greer and E. Thorbecke (1984), "Class of Decomposable Poverty Measures", Econometrica, 52(3), 761-776.

Gebremedhin, B. and S.M. Swinton (2000), "Reconciling Food-for-Work Project Feasibility with Food Aid Targeting in Tigray, Ethiopia”, Food Policy 26(1), 8595.

Gilligan, D. O. and J. Hoddinott (2007), "Is There Persistence in the Impact of Emergency Food Aid? Evidence on Consumption, Food Security, and Assets in Rural Ethiopia”, American Journal of Agricultural Economics, 89(2), 225-42.

Haddad, L. and M. Adato (2001), "How Effective do Public Works Programs Transfer Benefits to the Poor? Evidence from South Africa", Food Consumption and Nutrition Division Discussion Paper No. 108. International Food Policy Research Institute, Washington, DC.

Hecknam, J.J. and S. Navarro-Lozano (2004), "Using Matching, Instrumental Variables, and Control Functions to Estimate Economic Choice Models", Review of Economics and Statistics 86, 30-57.

Heckman, J.J., H. Ichimura and P.E. Todd (1997), "Matching as an Economic Evaluation Estimator: Evidence from Evaluating a Job Training Program", Review of Economic Studies 64, 605-54

Holden, S., B.C. Barret and F. Hagos (2006), "Food-for-Work for Poverty Reduction and the Promotion of Sustainable Land Use: Can it Work?", Environment and Development Economics 11(01), 15-38.

Jalan, J. and M. Ravallion (2000), "Is Transient Poverty Different? Evidence from Rural China", Journal of Development Studies 36(6), 82-100.

Jayne, T., J. Strauss, T. Yamano and D. Molla (2002), "Targeting of Food Aid in Rural Ethiopia: Chronic Need or Inertia?”, Journal of Development Economics, 68(2), 247-288.

Mirutse, D., H. Gebregiorgis and A. Selam (2006), "Female-Headed Households and Livelihood Intervention in Four Selected Weredas in Tigray, Ethiopia", Drylands Coordination Group (DCG) Report No. 44. 
MoARD (2004), "Productive Safety Net Program: Program of Implementation Manual", Ministry of Agriculture and Rural Development, Government of Ethiopia, Addis Ababa, Ethiopia.

Quisumbing, A.R. (2003), "Food Aid and Child Nutrition in Rural Ethiopia", World Development 31(7), 1309-24.

Ravallion, M. (1999), “Appraising Workfare”, World Bank Research Observer 14 (1), $31-48$.

Ravallion, M. and B. Bidani (1994), "How Robust is Poverty Profile?", The World Bank Economic Review 8(1), 75-102

Rosenbaum, P. and D.B. Rubin (1983), "The Central Role of the Propensity Score in Observational Studies for Causal Effects", Biometrika 70, 41-55.

Smith, J.A. and P.E. Todd (2005), "Does Matching Overcome LaLonde's Critique of Nonexperimental Estimators?", Journal of Econometrics 125, 305-53.

Sharp, K. (1997), "Targeting Food Aid in Ethiopia", Save the Children Fund (UK), Addis Ababa, Ethiopia.

Shorrocks, A.E. (1978), “The Measurement of Mobility”, Econometrica 46(5), 1013-23.

Solomon, A. (2006), "Does Food Aid Reach the Poor? New Evidence from Northern Ethiopia", A paper Presented at a Conference on International Agricultural Research for Development, October 11-13, University of Bonn, Germany.

Swanepoel, C. (2005), "Poverty and Poverty Dynamics in Rural Ethiopia", Stellenbosch Economic Working Papers 3

Yamano, T., H. Alderman and L. Christiaensen (2005), "Child Growth, Shocks and Food Aid in Rural Ethiopia", American Journal of Agricultural Economics 87(2), 273288. 